\title{
Pattern of ear nose and throat diaseses in a tertiary hospital of Dhaka city
}

\author{
Badhan Kumar Dey ${ }^{1}$, Anamika Datta², Mir Masudur Rhaman², MA Sayeed ${ }^{3}$ \\ ${ }^{I}$ Department of ENT \& Head-Neck Surgery, BIRDEM General Hospital, Dhaka, Bangladesh; \\ ${ }^{2}$ Department of Transfusion Medicine \& Clinical Haematology, BIRDEM General Hospital, Dhaka, \\ Bangladesh; ${ }^{3}$ Department of Community Medicine, Ibrahim Medical College, Dhaka, Bangladesh
}

\begin{abstract}
Background and objectives: The magnitude of health problems related to ear, nose and throat (ENT) in Bangladesh has not been estimated in a larger scale and very little is known about the prevalence and types of ENT diseases. Some studies, however, addressed the prevalence of otitis among school children and very few of them reported hearing defect. This study aims to assess the overall types of ENT diseases encountered by the otolaryngologists at a referral or tertiary hospital.
\end{abstract}

Methods: The cross sectional study was conducted in Bangladesh Institute of Research and Rehabilitation in Diabetes, Endocrine and Metabolic Disorders (BIRDEM). All patients registerd in the ENT-OPD from January to April in 2017 were included in the study for analysis. Diseases were diagnosed on the basis of clinical history, general and systemic examinations and relevant laboratory and imaging investigations.

Results: A total of $435(\mathrm{M}: \mathrm{F}=177: 258)$ registered patients were analyzed. 44 of them had no ENT diseases. Diseases of ear showed the highest prevalence $(41.1 \%)$ followed by that of throat $(31.7 \%)$ and nose $(17.1 \%)$. There was no significant difference in ear and nose diseases between male and female groups. The throat diseases were significantly higher in female than the male group (37.2\% vs.22.6\%, p=0.018). Regarding infections of the specific organs: suppurative otitis media was the most common (acute and chronic suppurative otitis media $25.5 \%$ ) followed by tonsillitis $(7.1 \%)$, rhinitis $(4.4 \%)$ and sinusitis $(1.4 \%)$. These infections showed no significant difference between male and female patients; neither there was any significant difference between the diabetic and non-diabetic groups.

Conclusion: Diseases of ear were most common followed by throat and nose. Both acute and chronic otitis media constituted one-fourth of all registered cases. The diabetic patients showed no increased risk for ENT diseases.

IMC J Med Sci 2018; 12(1): 22-26

\section{Introduction}

Several studies have reported the prevalence and types of ear, nose and throat (ENT) diseases among Bangladeshi population [1-6]. Some population based studies addressed chronic suppurative otitis media (CSOM) among children in Bangladesh. The comparison of CSOM in children showed higher prevalence in rural $(6.02 \%)$ than urban $(2.07 \%)$ area [1]. Other study among Bangladeshi rural children reported rate of CSOM as 5.2\% [4]. In two slum populations of Dhaka City, the prevalence of CSOM among children was $7.4 \%$ [6]. The types of ENT diseases varied from country to country. For Nigeria, the prevalence of diseases of ear, nose and throat were $62.7 \%, 23.0 \%$ and $9.6 \%$, respectively [7]. In Senegal, the rates were $22.8 \%$,

Address for Correspondence:

Dr. Badhan Kumar Dey, Registrar, Department of ENT \& Head-Neck Surgery, BIRDEM General Hospital, 122 Kazi Nazrul Islam Avenue, Shahbagh, Dhaka.E-mail: badhan407@gmail.com 
$54.6 \%$ and $22.4 \%$ [8] and in India, the rates were $36.6 \%, 23.5 \%$ and $16.58 \%$ respectively [9].

It is important to note that the disorders of ENT are not confined to these organs only but also affect quality of life rendering health care very expensive. For example, chronic sinusitis (CS) is a prevalent and disabling condition of the paranasal sinuses affecting approximately 31 million people in the United States with an estimated USD 8.6 billion health care expenditures [10]. CS is reported to affect quality of life more than other chronic conditions, such as congestive heart failure, chronic obstructive pulmonary disease (COPD), and chronic back pain [11-13]. Without objective evidence of inflammation, it is challenging to distinguish CS from conditions with overlapping symptoms, such as allergic rhinitis or migraine [14]. Furthermore, it is difficult to use symptoms alone to differentiate between CS subtypes, such as CS with nasal polyps and CS without nasal polyps [15]. Sometimes, ENT disorders are linked with other systemic illness like pemphigus vulgaris [16]. For Bangladesh, it may be important to consider ENT problems related to zoonotic diseases [17]. Because the Bangladeshi people are constantly exposed to zoonotic health hazards. Despite all these vulnerability of Bangladeshi people there is very little information in this regard. On the other hand, diabetes is thought to increase the risk and severity of ENT disorders. Very insufficient data on the diseases of ENT are available even in a referral hospital. This study addressed the characteristics and types of ENT diseases in a tertiary hospital.

\section{Methods}

This cross-sectional study was conducted in the department of ENT (otolaryngology) in BIRDEM general hospital (Bangladesh Institute of Research and Rehabilitation in Diabetes, Endocrine and Metabolic Disorders). BIRDEM is a national referral center for diabetes and other metabolic diseases. The ENT department has almost all standard diagnostic facilities to deal with diseases of ear, nose and throat. The department has both out-patient (ENT-OPD) and in-patient (hospital) wings and delivers services to diabetic as well as non-diabetic patients. This center registers more than twenty thousand patients per year.
All patients registered in the ENT-OPD from January 2017 to April 2017 were included in this study for analysis. Each patient underwent otolaryngological examinations. Diagnosis of diseases was based on clinical history, general and systemic examinations and relevant otolaryngological investigations. In relevant cases, throat, nasal or ear swabs were collected to identify the causative microorganisms in the Microbiological laboratory. Histopathological examinations were undertaken in the Department of Pathology. The Department of Radiology and Imaging helped in diagnosing sinusitis and CSOM.

\section{Results}

Overall, 435 (M:F=177:258) registered patients were analyzed for this study. Among them 44 patients have not been suffering from ENT diseases. The diseases of ear, nose and throat were $41.1 \%(\mathrm{M}: \mathrm{F}=45.2: 38.4), 17.1 \% \quad(20.3$ : $14.7)$ and $31.7 \%(22.6: 37.2)$ respectively [Table 1]. The distribution of diseases of ear, nose and throat according to age-quartile have been shown in Table 1. There was no difference between male and female patients for diseases of ear and nose. Only significant difference was observed in case of the throat diseases. The female patients had significantly higher throat diseases than the males $(p<0.05)$. This may be due to very high prevalence of throat diseases in the lowest age quartile $(<40$ years; $\mathrm{M}: \mathrm{F}=14.9$ : $35.3 ; \mathrm{p}=0.018)$.

The prevalence of tonsillitis, sinusitis, ASOM, CSOM, rhinitis and DNS according to sex and glycemic status (diabetic and non-diabetic: DM \& NDM) are shown in Table 2. Both types of otitis media (ASOM $13.3 \%$, CSOM 12.2\%) was the most prevalent (one-fourth) of all ENT patients while the least common ailment was sinusitis $(1.4 \%)$. The prevalence of tonsillitis was $7.1 \%$, rhinitis $4.4 \%$ and DNS $3.7 \%$. No significant difference was observed between male and female participants. There was no significant difference between diabetic and non diabetic participants. Out of total enrolled participants, $18.8 \%$ had different degree of hearing loss due to mechanical causes namely impacted wax, foreign body, etc. 
Table-1: Distribution of cases according to age and gender with overall ear, nose and throat diseases

\begin{tabular}{|c|c|c|c|c|c|c|c|c|}
\hline \multirow{2}{*}{$\begin{array}{c}\text { Age groups } ₫ \\
(\mathrm{yr})\end{array}$} & \multirow[b]{2}{*}{ Sex } & \multirow{2}{*}{$\begin{array}{c}\text { ENT } \\
\text { Disease } \\
*(\mathbf{Y} / \mathbf{N})\end{array}$} & \multicolumn{2}{|l|}{ Ear } & \multicolumn{2}{|l|}{ Nose } & \multicolumn{2}{|l|}{ Throat } \\
\hline & & & $\mathrm{n}(\%)$ & $* p$ & $\mathrm{n}(\%)$ & $* p$ & $\mathrm{n}(\%)$ & $* * p$ \\
\hline \multirow[t]{3}{*}{$<40$} & M & $47 / 7$ & $18(38.3)$ & & $15(31.9)$ & & $7(14.9)$ & \\
\hline & $\mathrm{F}$ & $68 / 9$ & $21(30.9)$ & $n s$ & $14(20.6)$ & $n s$ & $24(35.3)$ & 0.018 \\
\hline & Total & $115 / 16$ & 39 (33.9) & & $29(25.2)$ & & $31(26.0)$ & \\
\hline \multicolumn{9}{|l|}{$41-50$} \\
\hline & M & $43 / 4$ & $18(41.9)$ & & $9(20.9)$ & & $12(27.9)$ & \\
\hline & $\mathrm{F}$ & $102 / 7$ & $38(37.3)$ & $n s$ & $12(11.8)$ & $n s$ & $45(44.1)$ & $n s$ \\
\hline & Total & $145 / 11$ & $56(38.6)$ & & $21(14.5)$ & & $57(39.3)$ & \\
\hline \multicolumn{9}{|l|}{$51-60$} \\
\hline & M & $26 / 1$ & $12(46.2)$ & & $4(15.4)$ & & $9(34.6)$ & \\
\hline & $\mathrm{F}$ & $43 / 6$ & $22(51.2)$ & $n s$ & $4(9.3)$ & $n s$ & $11(25.6)$ & $n s$ \\
\hline & Total & $69 / 7$ & $34(49.3)$ & & 8 (11.6) & & $20(29.0)$ & \\
\hline \multicolumn{9}{|l|}{$61+$} \\
\hline & M & $61 / 7$ & $32(52.5)$ & & $8(13.1)$ & & $14(23.0)$ & \\
\hline & $\mathrm{F}$ & $45 / 3$ & $18(40.0)$ & $n s$ & $8(17.8)$ & $n s$ & $16(35.6)$ & $n s$ \\
\hline & Total & $106 / 10$ & $50(47.2)$ & & $16(15.1)$ & & $30(28.3)$ & \\
\hline \multicolumn{9}{|l|}{ Total } \\
\hline & $\mathbf{M}$ & $177 / 19$ & $80(45.2)$ & & $36(20.3)$ & & $42(22.6)$ & \\
\hline & $\mathbf{F}$ & $258 / 25$ & $99(38.4)$ & $n s$ & $38(14.7)$ & $n s$ & $96(37.2)$ & 0.041 \\
\hline & Total & $435 / 44$ & 179 (41.1) & & $74(17.1)$ & & $138(31.7)$ & \\
\hline
\end{tabular}

I - age-groups have been classified into quartiles. Other conditions namely thyroid diseases, cleft palate, genetic disorders were categorized in the Tableas 'No'ENT disease group. ${ }^{*} Y / N$-Yes/No. ** $p$ after chi-sq comparing sex.

Table-2: Distribution of tonsillitis, sinusitis, ASOM, CSOM, rhinitis and DNS according to gender and glycemic status (diabetes vs. non-diabetic groups)

\begin{tabular}{|c|c|c|c|c|c|c|c|c|c|c|c|c|c|}
\hline \multirow{2}{*}{ Parameters } & \multirow{2}{*}{$\begin{array}{c}\text { Total } \\
\mathrm{n}\end{array}$} & \multicolumn{2}{|c|}{ Tonsillitis } & \multicolumn{2}{|c|}{ Sinusitis } & \multicolumn{2}{|c|}{ ASOM } & \multicolumn{2}{|c|}{ CSOM } & \multicolumn{2}{|c|}{ Rhinitis } & \multicolumn{2}{|c|}{ DNS } \\
\hline & & $\mathrm{n}$ & $\%$ & $\mathrm{n}$ & $\%$ & $\mathrm{n}$ & $\%$ & $\mathrm{n}$ & $\%$ & $\mathrm{n}$ & $\%$ & $\mathrm{n}$ & $\%$ \\
\hline Male & 177 & 3 & 1.7 & 1 & 0.6 & 24 & 13.6 & 21 & 11.9 & 8 & 4.5 & 10 & 5.6 \\
\hline Female & 258 & 28 & 10.9 & 5 & 1.9 & 34 & 13.2 & 32 & 12.4 & 11 & 4.3 & 6 & 2.3 \\
\hline Total & 435 & 31 & 7.1 & 6 & 1.4 & 58 & 13.3 & 53 & 12.2 & 19 & 4.4 & 16 & 3.7 \\
\hline$*$ p value & & \multicolumn{2}{|c|}{0.001} & \multicolumn{2}{|c|}{ ns } & \multicolumn{2}{|c|}{ ns } & \multicolumn{2}{|c|}{ ns } & \multicolumn{2}{|r|}{ ns } & \multicolumn{2}{|r|}{ ns } \\
\hline NDM & 70 & 4 & 5.7 & 2 & 2.9 & 7 & 10.0 & 4 & 5.7 & 5 & 7.1 & 5 & 7.1 \\
\hline DM & 365 & 27 & 7.4 & 4 & 1.1 & 51 & 14.0 & 49 & 13.4 & 14 & 3.8 & 11 & $3 . .0$ \\
\hline Total & 435 & 31 & 7.1 & 6 & 1.4 & 58 & 13.3 & 53 & 12.2 & 19 & 4.4 & 16 & 3.7 \\
\hline$* \mathrm{p}$ value & & \multicolumn{2}{|r|}{ ns } & \multicolumn{2}{|c|}{ ns } & \multicolumn{2}{|c|}{ ns } & \multicolumn{2}{|c|}{ ns } & \multicolumn{2}{|r|}{ ns } & \multicolumn{2}{|r|}{ ns } \\
\hline
\end{tabular}




\section{Discussion}

This study attempted to determine the types and prevalence of specific types of ENT diseases encountered in a tertiary (national referral) hospital. In Bangladesh, most studies addressed ENT diseases among school children [1,3-6]. Tarafder et al addressed only hearing impairment [2].

Thus, this study possibly is the first to explore the types of ENT diseases commonly observed in a tertiary hospital. As there was no age limit it included both children and adult. The age below 20 years comprised $5 \%$ and below 40 years comprised $25 \%$. It was apparent that the study population represented a wide age range. Moreover, the study enabled us to assess the types of ENT ailments commonly referred to a tertiary hospital.

One-fourth of the participants had otitis, which was the highest ailments referred to ENT department of BIRDEM. This finding is consistent with the previous studies carried out in Bangladesh [1,3-5]. The prevalence of ENT diseases observed in this study are very much consistent with the findings of West Bengal [18]. Our findings showed that the diseases of ear, nose and throat were $41.1 \%$, $17.1 \%$ and $31.7 \%$ respectively. In West Bengal, Barman D et al reported almost similar results: otological, nasal and throat cases were $42.41 \%$, $28.98 \%$ and $28.60 \%$, respectively [18]. Hearing impairment due to mechanical causes (foreign body, impacted ear wax) of this study also simulates the past findings [2].

The study had some major limitations. It did not include some important and relevant risk factors [18-20]. Occupation could have given valuable information as well as zoonotic link to ENT diseases [17]. Likewise, family income and poor living conditions could also be a risk for specific ENT illness $[8,20]$.

This study revealed that otitis (ASOM and CSOM) was the most prevalent ailment registered in a tertiary health care center. Of the ENT diseases, highest number of patients presented with ear diseases followed by throat illnesses. The throat diseases were significantly higher in female than in the male participants. Hearing impairment was found mostly due to mechanical causes like foreign body and impacted wax. The diabetic patients showed no excess risk for ENT diseases. Further study may be undertaken considering these limitations. This study suggests that some important risk factors mentioned above (limitation) should be investigated and identified to improve ENT health care.

\section{Acknowledgements}

We are very grateful to all the employees of the Department of ENT, BIRDEM. We are also indebted to the Departments of Radiology and Imaging, Pathology, Microbiology and Clinical Biochemistry for their active cooperation.

\section{Author's contributions}

BKD was involved in patient selection, reception, registration, diagnosis and confirmation of diagnosis. AD was involved in literature review. MMR was involved in data entry, data editing, analysis and interpretation. MAS was involved in manuscript writing and overall supervision.

\section{Competing interest}

Authors declare no conflict of interest.

\section{Funding}

None

\section{References}

1. Shaheen MM, Nahar S. Comparison of chronic suppurative otitis media in rural and urban primary school children in Bangladesh. J Laryngol Otol. 2014; 128(6): 499-503. doi:10.1017/S0022215114001054.

2. Tarafder KH, Akhtar N, Zaman MM, Rasel MA, Bhuiyan MR, Datta PG. Disabling hearing impairment in the Bangladeshi population. J Laryngol Otol. 2015; 129(2): 126-135. doi:10.1017/S002221511400348X.

3. Alam MM, Ali MI, Habib MA, Siddique MA, Sanyal NP, Joarder AH. Otitis media with effusion in children admitted for adenoidectomy. Mymensingh Med J.2015; 24(2): 284-289. 
4. Shaheen MM, Raquib A, Ahmad SM. Chronic suppurative otitis media and its association with socio-econonic factors among rural primary school children of Bangladesh. Indian J Otolaryngol Head Neck Surg. 2012; 64(1): 36-41. doi: 10.1007/s12070-011-0150-9.

5. Roy E, Hasan KhZ, Haque F, Siddique AK, Sack RB. Acute otitis media during the first two years of life in a rural community in Bangladesh: a prospective cohort study. $J$ Health Popul Nutr. 2007; 25(4): 414-421.

6. Kamal N, Joarder AH, Chowdhury AA, Khan AW. Prevalence of chronic suppurative otitis media among the children living in two selected slums of Dhaka City. Bangladesh Med Res Counc Bull. 2004; 30(3): 95-104.

7. Fasunla AJ, Samdi M, Nwaorgu OG.An audit of ear, nose and throat diseases in a tertiary health institution in South-western Nigeria. Pan Afr Med J. 2013; 14: 1. doi: 10.11604/ pamj.2013.14.1.1092.

8. Tall H, Bah FY, Nasser T, Sambou A, Diallo BK. Ear, nose and thorat disorders in pediatric patients at a rural hospital in Senegal. Int $J$ Pediatr Otorhinolaryngol. 2017; 96: 1-3. doi:10.1016/j.ijporl.2017.02.019.

9. Singh A, Kumar S. A survey of ear, nose and throat disorders in rural India. Indian $J$ Otolaryngol Head Neck Surg. 2010; 62(2): 121-124. doi: 10.1007/s12070-010-0027-3.

10. Bhattacharyya $N$. Incremental health care utilization and expenditures for chronic rhinosinusitis in the United States. Ann OtolRhinolLaryngol. 2011; 120(7): 423-427.

11. Gliklich RE, Metson R. The health impact of chronic sinusitis in patients seeking otolaryngologic care. Otolaryngology - Head and Neck Surgery. 1995; 113(1): 104-109.

12. Macdonald KI, McNally JD, Massoud E. The health and resource utilization of Canadians with chronic rhinosinusitis. Laryngoscope. 2009; 119(1): 184-189.
13. Soler ZM, Wittenberg E, Schlosser RJ, et al. Health state utility values in patients undergoing endoscopic sinus surgery. Laryngoscope. 2011; 121(12): 2672-2678.

14. Fokkens WJ, Lund VJ, Mullol J, Bachert C, Alobid I, Baroody F, et al. The European position paper on rhinosinusitis and nasal polyps 2012. Rhinology. 2012 Suppl; 23: 1-299.

15. Tan BK, Kern RC, Schleimer RP, Schwartz BS. Chronic rhinosinusitis: the unrecognized epidemic. Am J RespirCrit Care Med. 2013; 188(11): 1275-1277.

16. Fawzy MM, Hegazy RA, Abdel Fattah AF. Ear, nose, and throat involvement in Egyptian pemphigus vulgaris patients: A step towards a better management. Int J Dermatol. 2013; 52(10): 1268-1273. doi: 10.1111/j.13654632.2012.05846.x

17. Galletti B, Mannella VK, Santoro R, Rodriguez-Morales AJ, Freni F, Galletti C, et $a l$. Ear, nose and throat (ENT) involvement in zoonotic diseases: a systematic review. J Infect Dev Ctries. 2014; 8(1): 17-23. doi: 10.3855/ jidc. 4206 .

18. Barman D, Maridal S, Goswami S, Hembram R. Three years audit of the emergency patients in the department of ENT of a rural medical college. J Indian Med Assoc. 2012; 110(6): 370-4.

19. Smith SS, Ference EH, Evans CT, Tan BK, Kern RC, Chandra RK. The prevalence of bacterial infection in acute rhinosinusitis: a Systematic review and meta-analysis. Laryngoscope. 2015; 125(1): 57-69. doi: 10.1002/lary.24709

20. Sundaresan AS, Hirsch AG, Storm M, Tan BK, Kennedy TL, Greene JS, et al. Occupational and environmental risk factors for chronic rhinosinusitis: A systematic review. Int Forum Allergy Rhinol. 2015; 5(11): 996-1003. 